\title{
SIMPLE AND NOVEL HYBRID RANDOM PWM ALGORITHM FOR DTC-INDUCTION MOTOR DRIVE FOR REDUCED ACOUSTICAL NOISE
}

\author{
P. NAGASEKHARA REDDY*, J. AMARNATH* ${ }^{* *}$ P. LINGA REDDY ${ }^{* * *}$ \\ *E.E.E. Department, M.G.I.T., Hyderabad, Andhra Pradesh, India, e-mail: pnsreddy04@gmail.com \\ ${ }^{* *}$ E.E.E. Department, J.N.T. University, Hyderabad, Andhra Pradesh, India, e-mail: amarnathjinka@rediffmail.com \\ ${ }^{* *}$ E.E.E. Department, K.L. University, Guntur, Andhra Pradesh, India
}

\begin{abstract}
A simple and novel hybrid random PWM algorithm for direct torque controlled induction motor drive for reduced acoustical noise and harmonic distortion is presented in this paper to reduce the complexity of the classical space vector approach. The proposed algorithm is developed by using the imaginary switching times, which does not require angle and sector information. In order to get the randomization effect, the proposed algorithm uses discontinuous pulsewidth modulation maximum (DPWMMAX) algorithm in conjunction with the space vector pulsewidth modulation (SVPWM) algorithm. The harmonic analysis of the two switching sequences is carried out and by comparing each other in each sampling time interval, the proposed algorithm selects a suitable switching sequence. In the proposed algorithm by changing the factor $\mu$, the switching sequences of SVPWM and DPWMMAX algorithms are generated. The proposed PWM algorithm uses 0127 and 721 sequences when $\mu$ value takes 0.5 and 0 respectively. As the zero state time is varied randomly according to the operating sequence, randomization effect will occur, which results in reduced dominating harmonics and hence gives reduced acoustical noise. To validate the proposed PWM algorithm, the numerical simulation studies have been carried out and results are presented and compared. The simulation results confirm the effectiveness of the proposed algorithm.
\end{abstract}

Keywords: DTC, imaginary switching times, random PWM, stator flux ripple, SVPWM

\section{INTRODUCTION}

After the invention of field oriented control (FOC) [1] algorithm, the induction motor drives are becoming popular in many industrial applications. But, the FOC is more complex due to the usage of reference frame transformation. To reduce the complexity of FOC, a simple control technique known as direct torque control (DTC) is invented by Takahashi in 1980s [2]. Though the operating principles of FOC and DTC are different, both techniques give effective control of flux and torque. These two control strategies have been implemented in many industrial applications successfully. The detailed comparison between FOC and DTC is given in [3]. Due to the absence of reference frame transformations, DTC is simple when compared with the FOC. Though DTC gives superior torque performance, it gives variable switching frequency of the inverter and large steady state ripple in torque, current and flux.

To improve the torque and current ripple, several pulsewidth modulation (PWM) algorithms have been developed by several researchers. A detailed survey of these PWM algorithms is given in [4]. These PWM algorithms can be classified into two categories such as triangular comparison approach and space vector approach. However, the space vector approach is more popular as it offers more advantages when compared with the triangular comparison approach [5]-[6]. Hence, the space vector PWM (SVPWM) algorithm is attracting many researchers nowadays. Though the SVPWM algorithm based DTC gives reduced harmonic distortion when compared with the conventional DTC, it gives dominating harmonics around the switching frequency. Hence, the acoustical noise of the motor is more. To reduce the acoustical noise of the drive, recently, random PWM (RPWM) algorithms are becoming popular. Various type of RPWM algorithms have been discussed in [7][10]. The RPWM algorithms randomize the pulse pattern or switching frequency by using a random number generator.

The standard SVPWM algorithm distributes the zero state time equally among the two possible zero voltage vectors. By utilizing the freedom in zero state time distribution various PWM algorithms can be generated as explained in [11]-[19]. In many applications an efficient PWM algorithm is required, which gives less harmonic distortion and acoustical noise. Hence, in recent years many researchers have been concentrated on the harmonic analysis of PWM algorithms. To calculate the harmonic analysis of the algorithms a time domain analysis has been given in [11]-[16], [18]-[19] by using the notion of stator flux ripple and current ripple. However, the PWM algorithms, which are discussed so far, use the angle and sector information, which increase the complexity involved in the algorithm. To reduce the complexity, a novel approach is presented in [17]-[19] by using the concept of imaginary switching times.

This paper presents a simplified hybrid random PWM algorithm, which uses two switching sequences and selects one sequence in each sampling time period that results in reduced harmonic distortion.

\section{PROPOSED SWITHCING SEQUENCES}

To reduce the complexity involved in the SVPWM, the proposed switching sequences are developed by using the concept imaginary switching times. The imaginary switching times are proportional to the instantaneous values of the sampled reference phase voltages. These can be calculated as.

$T_{a n}=\frac{T_{s}}{V_{d c}} V_{a n} ; T_{b n}=\frac{T_{s}}{V_{d c}} V_{b n} ; T_{c n}=\frac{T_{s}}{V_{d c}} V_{c n}$ 
To calculate the switching times of the active and zero voltage vectors, in every sampling time period maximum $\left(\operatorname{Max}\left(T_{a n}, T_{b n}, T_{c n}\right)\right)$, minimum $\left(\operatorname{Min}\left(T_{a n}, T_{b n}, T_{c n}\right)\right)$ and middle values $\left(\operatorname{Mid}\left(T_{a n}, T_{b n}, T_{c n}\right)\right)$ of imaginary switching times are evaluated. Then the active voltage vector and zero voltage vector switching times can be given as in (2)(4). [18]

$$
\begin{aligned}
& T_{1}=T_{\text {max }}-T_{\text {mid }} \\
& T_{2}=T_{\text {mid }}-T_{\text {min }} \\
& T_{Z}=T_{s}-T_{1}-T_{2}
\end{aligned}
$$

Thus, the active state and zero state times can be calculated in a simple by using imaginary switching times.

However, the SVPWM algorithm distributes the zero state time equally in every sampling time period. By utilizing the unequal distribution of zero voltage vector switching times, various PWM algorithms can be generated. To generate the proposed switching sequences, the zero state time durations can be modified as $T_{0}=\mu T_{Z}$ for $V_{0}$ voltage vector and $T_{7}=(1-\mu) T_{Z}$ for $V_{7}$ voltage vector. By varying the $\mu$ value between 0 and 1 , various PWM algorithms can be generated. The SVPWM and DPWMMAX algorithms can be generated for $\mu=0.5$ and 0 respectively. These algorithms use 0127-7210 and 721-127 sequences in the first sector and so on. In each sampling time interval, the SVPWM algorithm has three number of switchings and whereas for the DPWMMAX algorithm is two. Hence, to get the same average switching frequency of the inverter, a sampling time interval is taken as $T_{S}=T$ for the SVPWM algorithm, while $T_{S}=(2 T / 3)$ for the DPWMMAX algorithm.

\section{PROPOSED HYBRID RPWM ALGORITHM}

\subsection{Analysis of Harmonic Distortion}

The total harmonic distortion (THD) of the line current is a widely used measure for the quality of current waveform. The quality of the line current waveform can be directly determined in time domain by integrating the ripple voltages. This method of analysis can be applied for any PWM switching sequences. In the space vector approach, the reference voltage vector is constructed in an average manner but not in an instantaneous manner. The actual value of the stator voltage differs from the applied voltage. Hence, there is always an instantaneous error voltage vector. The error voltage vector is defined as given in (6)

$$
V_{\text {rip }}=V_{k}-V_{\text {ref }}, k=0,1, \ldots 7
$$

where ' $k$ ' is the $k^{\text {th }}$ voltage vector. The active voltage vectors $\left(\mathrm{V}_{1}, \mathrm{~V}_{2}, \ldots \mathrm{V}_{6}\right)$ can be defined as $V_{k}=\frac{2}{3} V_{d c} e^{j(k-1) \frac{\pi}{3}}$.

The ripple voltage vectors and trajectory of the stator flux ripple can be represented in a complex plane as shown in Fig. 1.

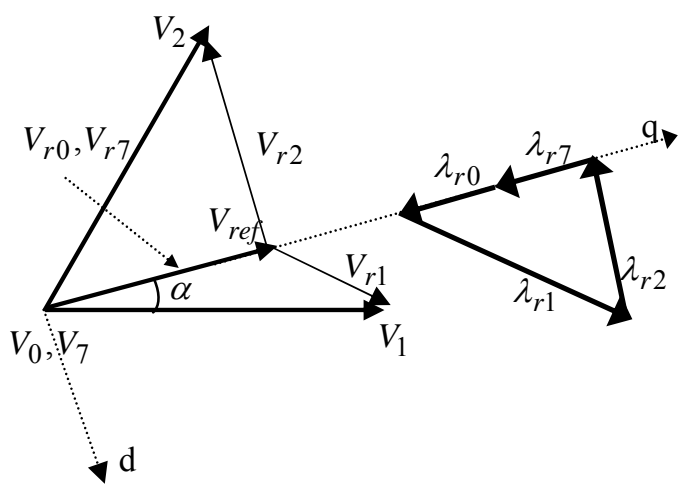

Fig. 1 Ripple voltage vectors and trajectory of stator flux ripple

The stator flux ripple vectors corresponding to the voltage ripple vectors are given by [19]

$$
\begin{aligned}
\lambda_{r 1}= & \left(\frac{2}{3} V_{d c} \sin \alpha\right) T_{1}+j\left(\frac{2}{3} V_{d c} \cos \alpha-V_{r e f}\right) T_{1} \\
\lambda_{r 2}= & -\left(\frac{2}{3} V_{d c} \sin \left(60^{\circ}-\alpha\right)\right) T_{2} \\
& +j\left(\frac{2}{3} V_{d c} \cos \left(60^{\circ}-\alpha\right)-V_{r e f}\right) T_{2} \\
\lambda_{r 0}= & -j V_{r e f} T_{0} \\
\lambda_{r 7}= & -j V_{r e f} T_{7}
\end{aligned}
$$

The above stator flux ripple vectors are normalized to $\lambda_{b}=\frac{2 V_{d c}}{\pi}$ for further simplification. The final flux ripple vectors expressions can be obtained in terms of imaginary switching times and modulation index as given in (10) (13).

$$
\begin{aligned}
& \lambda_{r 1}=\frac{\pi^{2}}{6 \sqrt{3} M_{i}} \frac{T_{1} T_{2}}{T_{s}}+j\left(\frac{\pi^{2}\left(2 T_{1}^{2}+T_{1} T_{2}\right)}{18 M_{i} T_{s}}-M_{i} T_{1}\right) \\
& \lambda_{r 2}=-\frac{\pi^{2}}{6 \sqrt{3} M_{i}} \frac{T_{1} T_{2}}{T_{s}}+j\left(\frac{\pi^{2}\left(2 T_{2}^{2}+T_{1} T_{2}\right)}{18 M_{i} T_{s}}-M_{i} T_{2}\right) \\
& \lambda_{r 0}=-j M_{i} T_{0} \\
& \lambda_{r 7}=-j M_{i} T_{7}
\end{aligned}
$$

Then the rms stator flux ripple over a sampling time period can be calculated as

$$
\lambda^{2}(\mathrm{rms})=\frac{1}{T_{s}} \int_{0}^{T_{s}} \lambda_{r}^{2} d t=\frac{1}{3 T_{s}}\left(\lambda_{11}^{2}+\lambda_{12}^{2}+\lambda_{13}^{2}\right)
$$

where

$$
\begin{aligned}
& \lambda_{11}^{2}=\frac{\pi^{4}}{91\left(M_{i} T_{s}\right)^{2}}\left(T_{1}^{5}+2 T_{1}^{3} T_{2}^{2}+2 T_{1}^{4} T_{2}+T_{1}^{2} T_{2}^{3}\right) \\
& \lambda_{12}^{2}=\frac{\pi^{2}}{18 T_{s}}\left\{\begin{array}{l}
4 T_{1}^{4}+6 T_{1}^{3}\left(T_{0}+T_{2}\right) \\
-2 T_{1} T_{2}\left(T_{1} T_{7}-T_{1} T_{2}-T_{0} T_{2}\right) \\
+7 T_{0} T_{1}^{2} T_{2}-T_{1} T_{21}^{2} T_{7}
\end{array}\right\}
\end{aligned}
$$




$$
\lambda_{13}^{2}=M_{i}^{2}\left\{\begin{array}{l}
\left(T_{0}+T_{1}\right)^{3}+T_{7}^{3}+T_{2}\left(T_{0}^{2}+T_{1}^{2}\right) \\
+2 T_{0} T_{1} T_{2}-T_{2} T_{7}\left(T_{0}+T_{1}\right)
\end{array}\right\}
$$

By employing (14), the modulation index and angle dependent mean square stator flux ripple of SVPWM and DPWMMAX algorithms can be easily computed and graphically illustrated as shown in Fig. 2 - Fig. 4.

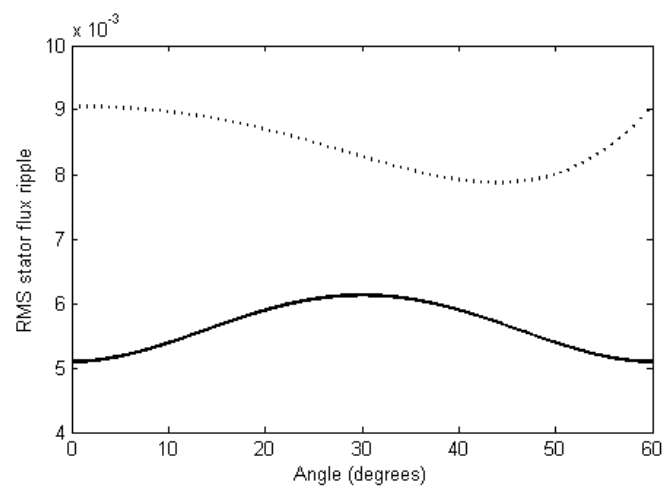

Fig. 2 Variation of stator flux ripple for SVPWM (continuous line) and DPWMMAX (dotted line) algorithms over the first sector at $M_{i}=0.4$

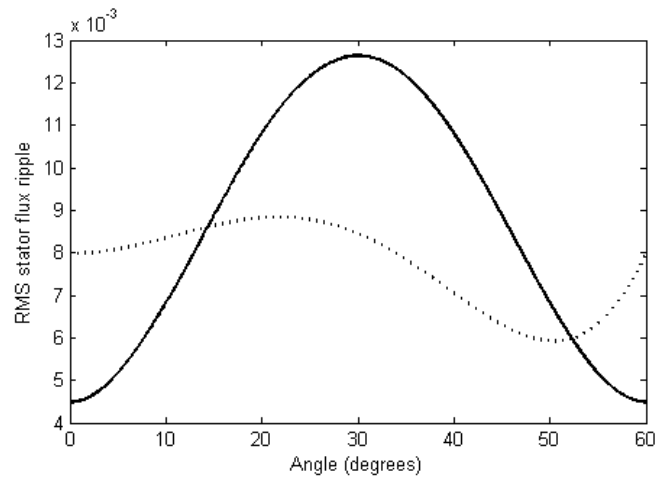

Fig. 3 Variation of stator flux ripple for SVPWM (continuous line) and DPWMMAX (dotted line) algorithms over the first sector at $M_{i}=0.7$

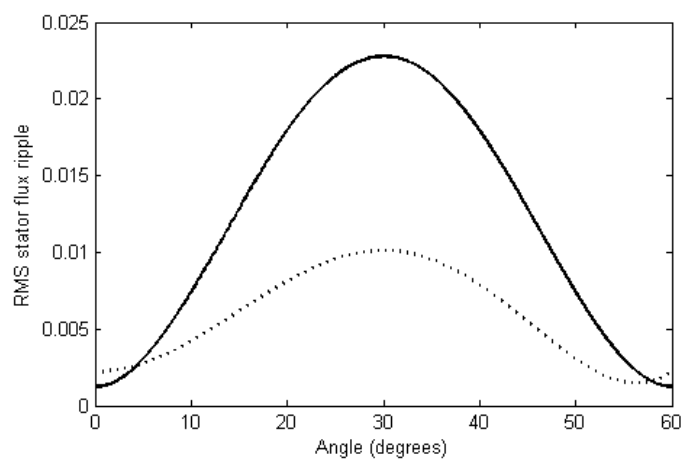

Fig. 4 Variation of stator flux ripple for SVPWM (continuous line) and DPWMMAX (dotted line) algorithms over the first

$$
\text { sector at } M_{i}=0.906
$$

Figs. $2-4$ compare the rms harmonic flux characteristics of the two switching sequences at different modulation indices. From these figures, it can be observed that the SVPWM provides superior performance in the low modulation range and as the modulation index increases, the performance of DPWMMAX method significantly improved.

\subsection{Proposed Hybrid RPWM Algorithm}

From the stator flux ripple characteristics, it can be observed that at lower modulation indices, the SVPWM algorithm gives superior performance whereas at higher modulation indices the DPWMMAX algorithm gives superior performance. To minimize the harmonic distortion in the line current, the rms stator flux ripple over every sampling time period should be reduced. The development of proposed PWM technique for reduced harmonic distortion involves determination of superior performance for each sequence. The zone of superior performance for a given sequence is the spatial zone within a sector where the given sequence results in less mean square stator flux ripple than the other sequence considered.

In the proposed PWM algorithm, in every sampling time period the rms stator flux ripples are compared with each other and the sequence, which has less rms stator flux ripple is applied to minimize the total harmonic distortion (THD). As the proposed PWM algorithm randomize the time duration of zero state time, it gives spread spectra and gives reduced amplitude for dominating harmonics around switching frequencies. Hence, the acoustical noise of the induction motor also can be reduced. Thus, the proposed PWM algorithm uses the DPWM algorithms in conjunction with SVPWM algorithm.

\section{PROPOSED HYBRID RPWM BASED DTC}

The block diagram of the proposed hybrid RPWM algorithm based DTC is as shown in Fig. 5. In the proposed method, the d-axis and q-axis components of the reference voltage vector can be obtained as follows:

Reference values of the d-axis and q-axis stator fluxes and actual values of the $\mathrm{d}$-axis and q-axis stator fluxes are compared in the reference voltage vector calculator block and hence the errors in the d-axis and q-axis stator flux vectors are obtained as in (18) - (19).

$$
\begin{aligned}
& \Delta \psi_{d s}=\psi_{d s}^{*}-\psi_{d s} \\
& \Delta \psi_{q s}=\psi_{q s}^{*}-\psi_{q s}
\end{aligned}
$$

The knowledge of flux error and stator ohmic drop allows the determination of appropriate reference voltage space vectors as given in (20)-(21).

$$
\begin{gathered}
V_{d s}^{*}=R_{s} i_{d s}+\frac{\Delta \psi_{d s}}{T_{s}} \\
V_{q s}^{*}=R_{s} i_{q s}+\frac{\Delta \psi_{q s}}{T_{s}}
\end{gathered}
$$

where, $T_{\mathrm{s}}$ is the duration of subcycle or sampling period and it is a half of period of the switching frequency. These d-q components of the reference voltage vector are fed to the PWM block. In PWM block, these two-phase voltages then converter into three-phase voltages. Then, the switching times are calculated. 


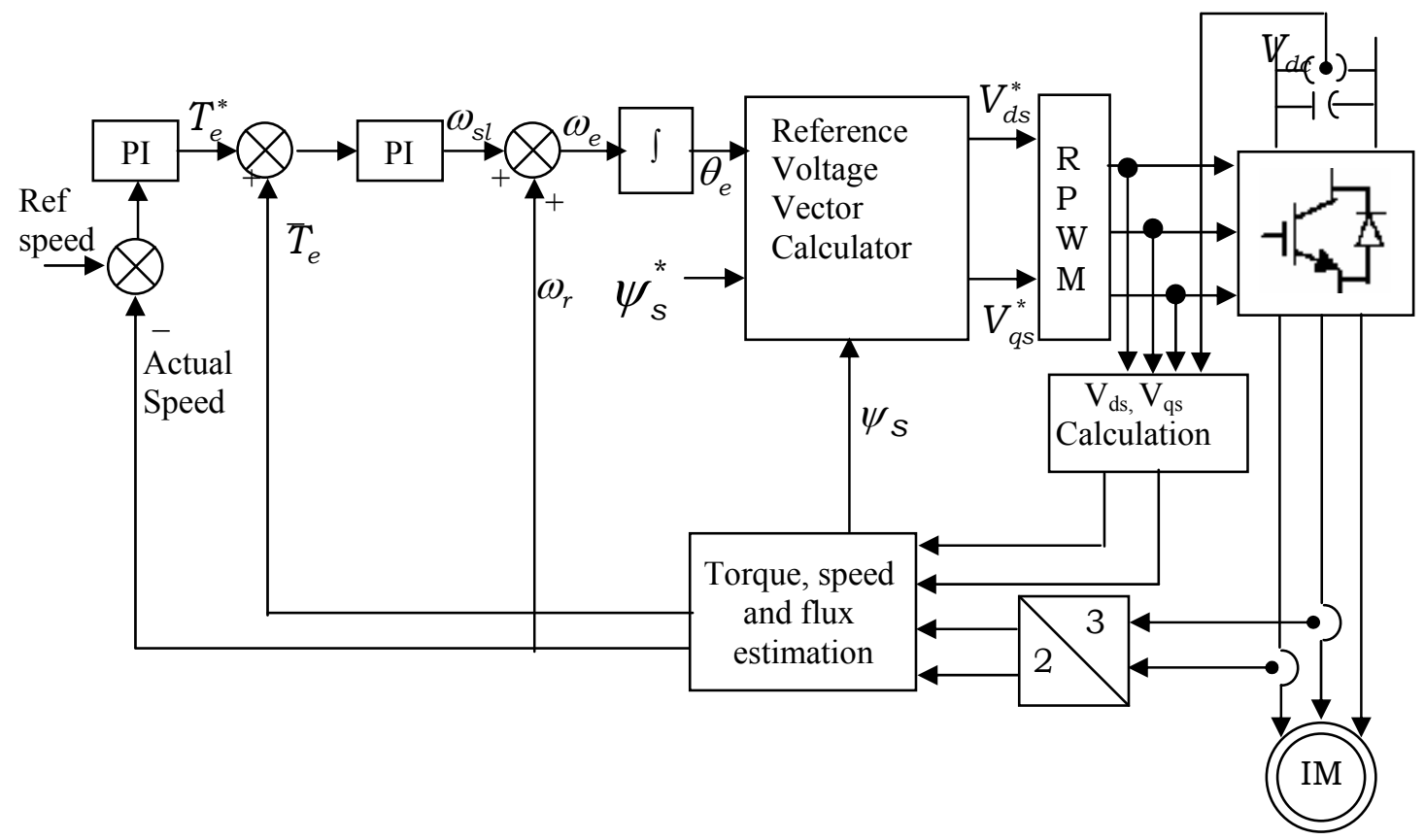

Fig. 5 Block diagram of proposed PWM based DTC

\section{SIMULATION RESULTS AND DISCUSSION}

To verify the proposed hybrid RPWM algorithm, the numerical simulation studies have been carried out using MATLAB. For the simulation studies, the average switching frequency of the inverter is taken as $5 \mathrm{kHz}$. The induction motor used in this case study is a $4 \mathrm{~kW}, 400 \mathrm{~V}$, $1470 \mathrm{rpm}$, 4-pole, $50 \mathrm{~Hz}$, 3-phase induction motor having the following parameters: $\mathrm{R}_{\mathrm{s}}=1.57 \Omega, \mathrm{R}_{\mathrm{r}}=1.21 \Omega, \mathrm{L}_{\mathrm{s}}=$ $0.17 \mathrm{H}, \mathrm{L}_{\mathrm{r}}=0.17 \mathrm{H}, \mathrm{L}_{\mathrm{m}}=0.165 \mathrm{H}$ and $\mathrm{J}=0.089 \mathrm{Kg} . \mathrm{m}^{2}$.

The steady state plots of conventional DTC methods are shown in Fig. 6 and corresponding line current harmonic spectra is shown in Fig. 7. From Fig. $6-7$, it can be observed that the conventional DTC gives large ripple in torque, flux and current. Moreover, the harmonic distortion is also high. To overcome these drawbacks, SVPWM algorithm is used for DTC. The steady state plots of SVPWM algorithm based DTC are given in Fig. 8 and the harmonic spectra of line current is given in Fig. 9. From the harmonic spectra, it can be observed that the SVPWM algorithm gives considerable amplitude of dominating harmonics around switching frequency. Hence, the SVPWM algorithm gives more acoustical noise/electromagnetic interference. Hence, to reduce the acoustical noise and harmonic distortion, a simplified hybrid RPWM algorithm is proposed in this paper. The simulation results at various conditions such as starting, steady state, step change in load change and speed reversal for proposed hybrid RPWM algorithm based DTC are shown from Fig. 10 to Fig. 14. From the simulation results, it can be observed that the proposed PWM algorithm gives good performance when compared with the SVPWM algorithm. Moreover, the proposed hybrid RPWM algorithm gives wide spread harmonic spectrum and gives reduced amplitudes of dominating harmonics. Hence, the proposed PWM algorithm gives reduced acoustical noise and reduced harmonic distortion when compared with the SVPWM algorithm.
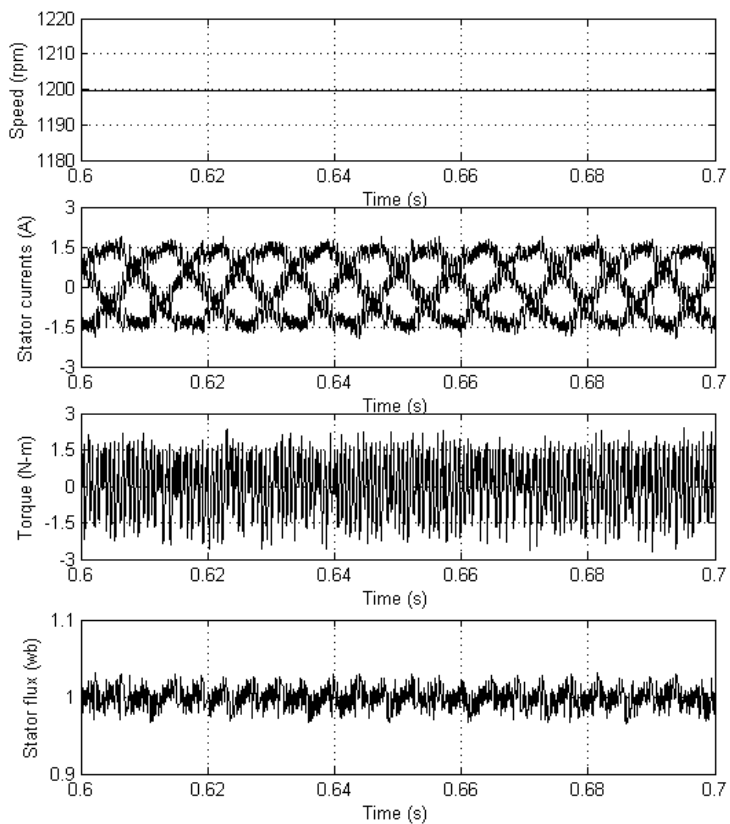

Fig. 6 Steady state plots of conventional DTC

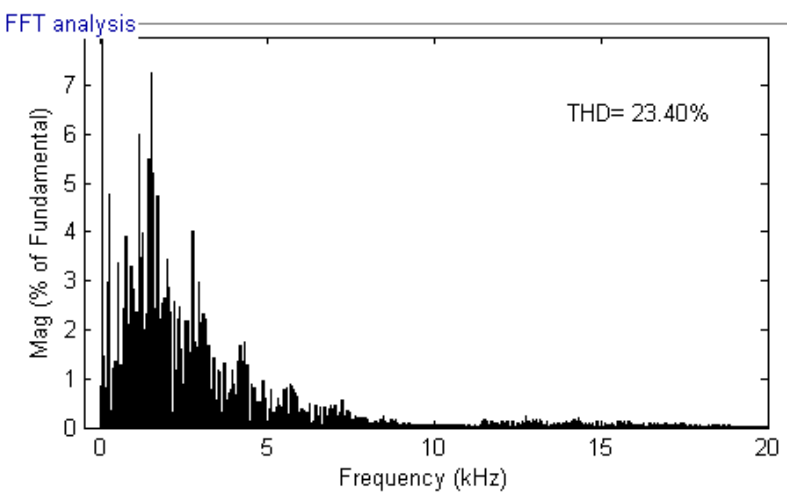

Fig. 7 Harmonic spectra of line current of conventional DTC 

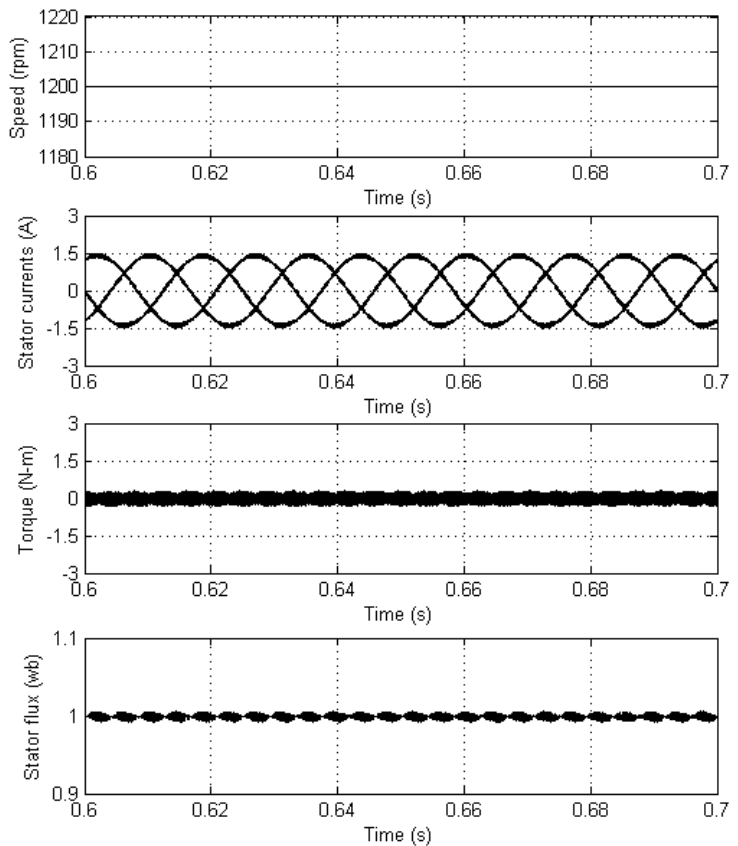

Fig. 8 Steady state plots of SVPWM algorithm based DTC

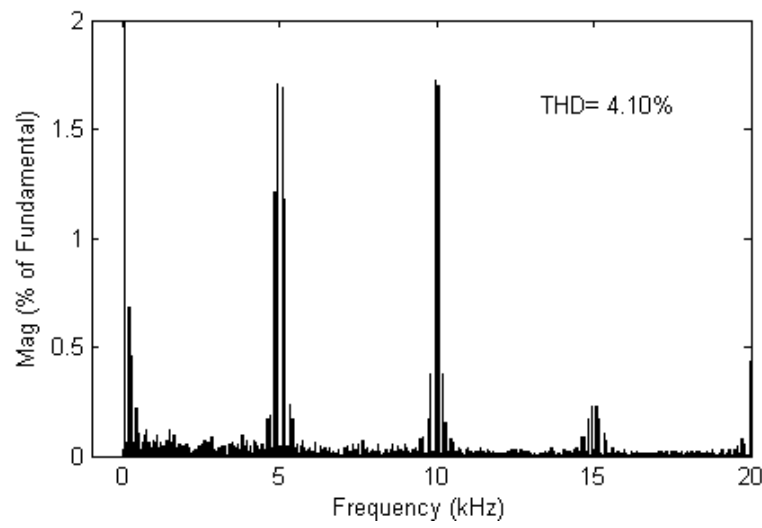

Fig. 9 Harmonic spectra of line current of SVPWM based DTC
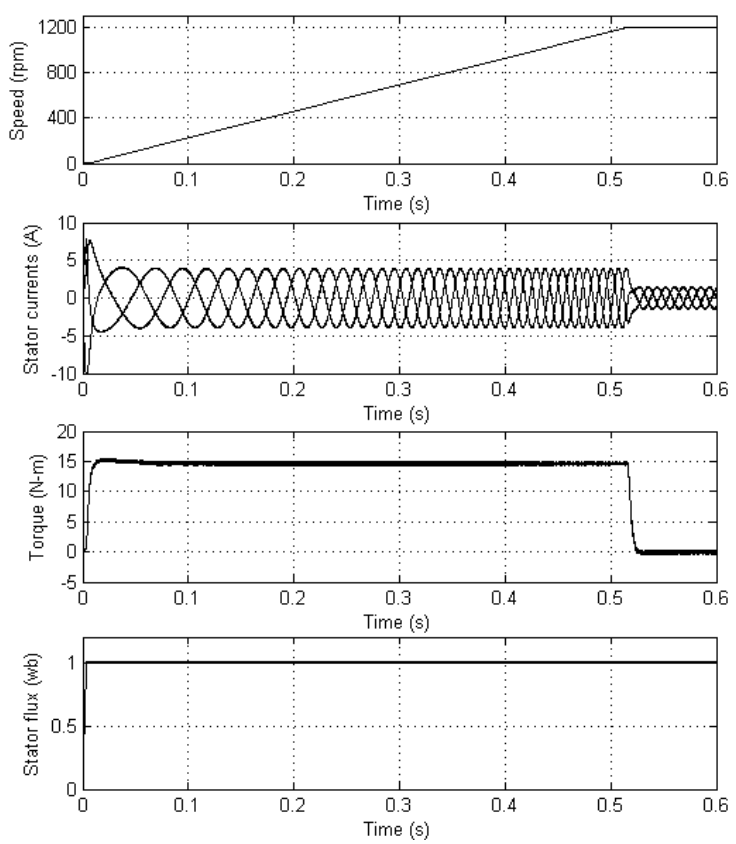

Fig. 10 starting transients proposed PWM algorithm based DTC
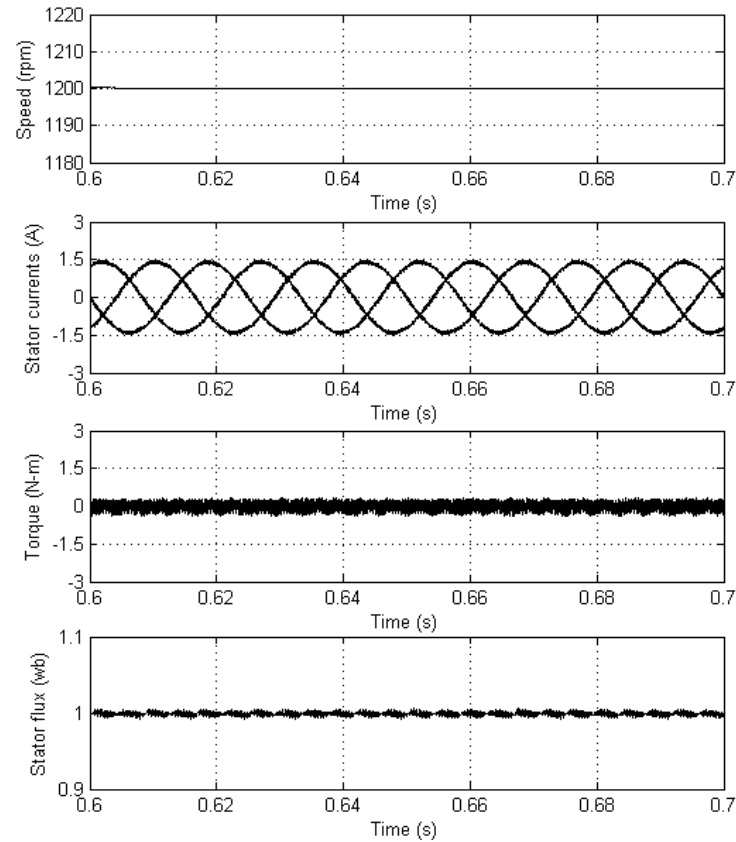

Fig. 11 Steady state plots of proposed PWM algorithm based DTC

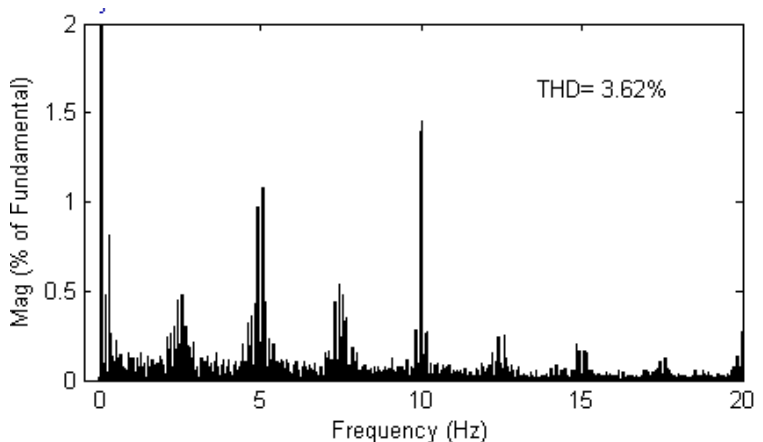

Fig. 12 Harmonic spectra of line current of proposed PWM based DTC
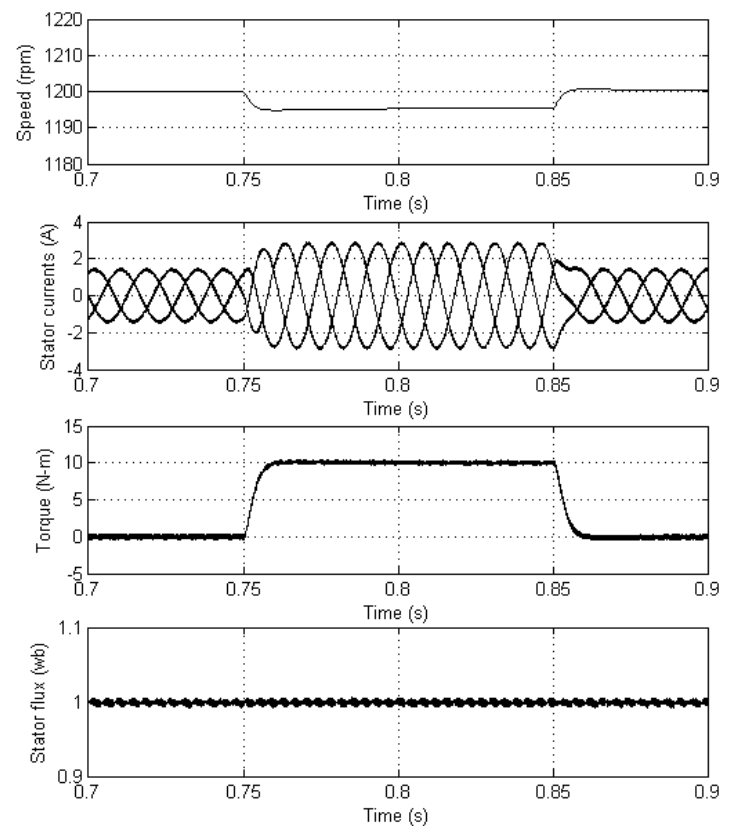

Fig. 13 Transients during step change in load for proposed PWM based DTC (a load torque of $10 \mathrm{~N}-\mathrm{m}$ is applied at $0.75 \mathrm{~s}$ and removed at $0.85 \mathrm{~s}$ ) 

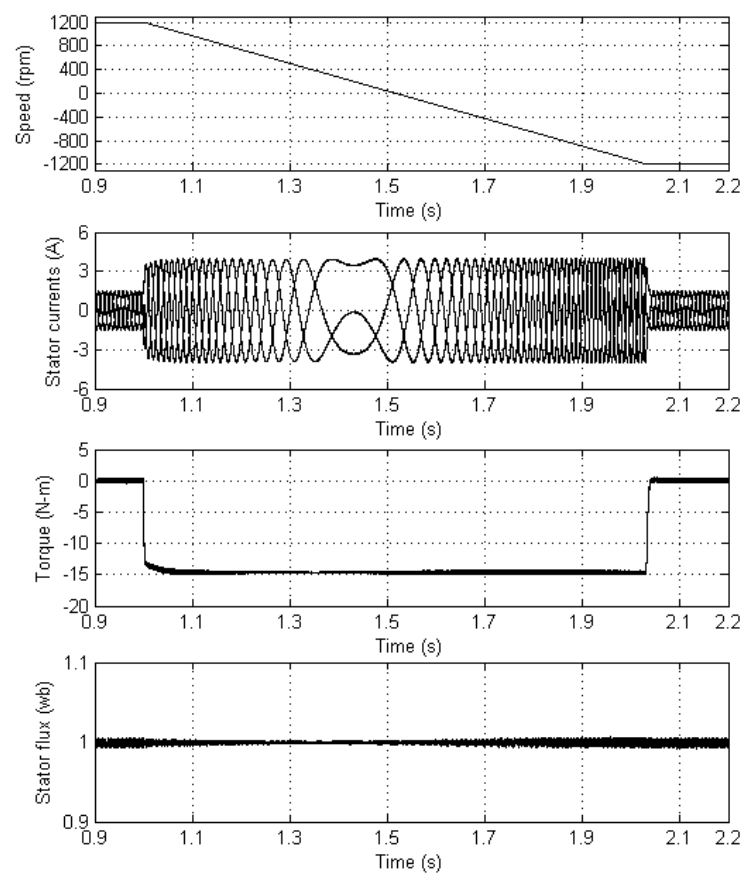

Fig. 14 Transients during speed reversal operation of proposed PWM based DTC (a load torque of $10 \mathrm{~N}-\mathrm{m}$ is applied at $0.75 \mathrm{~s}$ and removed at $0.85 \mathrm{~s}$ )

\section{CONCLUSIONS}

In earlier days to reduce the drawbacks of conventional DTC technique, SVPWM algorithm is used. As the SVPWM algorithm gives considerable dominating harmonics around switching frequency, it generates more acoustical noise and gives more harmonic distortion. Hence, to reduce the acoustical noise and harmonic distortion, a simplified hybrid RPWM algorithm is presented in this paper for direct torque controlled induction motor drive. The proposed PWM algorithm selects suitable switching sequence based on the stator flux ripple value. Thus, the proposed PWM algorithm gives randomization of zero state time. Hence, the proposed PWM algorithm gives spread spectra and gives reduced amplitude of dominating harmonics when compared with the SVPWM algorithm. The simulation results confirm the superiority of proposed PWM algorithm when compared with the SVPWM algorithm.

\section{REFERENCES}

[1] BLASCHKE, F.: The principle of field orientation as applied to the new transvector closed loop control system for rotating-field machines, Siemens Review, 1972, pp. 217-220.

[2] TAKAHASHI, I. - NOGUCHI, T.: A new quickresponse and high-efficiency control strategy of an induction motor, IEEE Trans. Ind. Appl., Vol. IA22, No.5, Sep./Oct. 1986, pp. 820-827.

[3] CASADEI, D. - PROFUMO, F. - SERRA, G. TANI, A.: FOC and DTC: Two Viable Schemes for Induction Motors Torque Control, IEEE Trans. Power Electron., Vol. 17, No. 5, Sep. 2002, pp. 779-787.
[4] HOLTZ, J.: Pulsewidth modulation - A survey, IEEE Trans. Ind. Electron., Vol. 39, No. 5, Dec. 1992, pp. 410-420.

[5] van der BROECK, H. W. - SKUDELNY, H.-Ch. STANKE, G. V.: Analysis and realization of a pulsewidth modulator based on voltage space vectors, IEEE Trans. Ind. Applicat., Vol. 24, No. 1, Jan./Feb. 1988, pp. 142-150.

[6] NARAYANAN, G. - RANGANATHAN, V. T.: Triangle comparison and space vector approaches to pulsewidth modulation in inverter fed drive, Journal of Indian Institute of Science, Sept./Oct. 2000, pp. 409-427.

[7] TRZYNADLOWSKI, A. M. - BLAABJERG, F. PEDERSEN, J. K. - KIRLIN, R. L. - LEGOWSKI, S.: Random pulse width modulation techniques for converter-fed drive systems-a review, IEEE Trans. Ind. Appl., Vol. 30, No. 5, 1994, pp. 1166-1174.

[8] BECH, M. M. - BLAABJERG, F. - PEDERSEN, J. K.: Random modulation techniques with fixed switching frequency for three-phase power converters, IEEE Trans. Power Electron., Vol. 15, No. 4, pp. 753-761, July, 2000.

[9] NA, S.-H. - JUNG, Y.-G. - LIM, Y.-C. - YANG, S.-H.: Reduction of audible switching noise in induction motor drives using random position space vector PWM, IEE Proc. - Electr. Power Appl., Vol. 149, No. 3, pp. 195-200, May, 2002.

[10] TRZYNADLOWSKI, A. M. - BORISOV, K. YUAN LI - LING QIN: A novel random PWM technique with low computational overhead and constant sampling frequency for high-volume, lowcost applications, IEEE Trans. Power Electron., Vol. 20, No. 1, pp. 116-122, Jan. 2005.

[11] HAVA, A. M. - KERKMAN, R. J. - LIPO, T.A.: Simple analytical and graphical methods for carrier-based PWM-VSI drives, IEEE Trans. Power Electron., Vol. 14, No. 1, Jan. 1999, pp. 4961.

[12] BLASKO, V.: Analysis of a hybrid PWM based on modified space-vector and triangle-comparison methods, IEEE Trans. Ind. Applicat., Vol. 33, No. 3, May/June 1997, pp. 756-764.

[13] NARAYANAN, G. - RANGANATHAN, V. T.: Analytical evaluation of harmonic distortion in PWM AC drives using the notion of stator flux ripple, IEEE Trans. Power Electron., Vol. 20, No. 2, March 2005, pp. 466-474.

[14] DI ZHAO - PAVAN KUMAR HARI, V. S. S. NARAYANAN, G.: Space Vector Based Hybrid Pulse Width Modulation Techniques for Reduced Harmonic Distortion and Switching Loss, IEEE Transactions on Power Electron., Vol. 25, Issue 4, March 2010, pp. 760-774.

[15] CASADEI, D. - SERRA, G. - TANI, A. - ZARRI, L.: Theoretical and experimental analysis for the RMS current ripple minimization in induction motor drives controlled by SVM technique, IEEE 
Trans. Ind. Electron., Vol. 51, No. 5, Oct. 2004, pp. 1056-1065.

[16] BASU, K. - SIVA PRASAD, J. S. NARAYANAN, G.: Minimization of torque ripple in PWM ac drives, IEEE Trans. Ind. Electron., Vol. 56, No. 2, pp. 553-558, Feb. 2009.

[17] DAE-WOONG CHUNG - JOOHN-SHEOK KIM - SEUNG-KI SUL: Unified voltage modulation technique for real-time three-phase power conversion, IEEE Trans. Ind. Applicat., Vol. 34, No. 2, Mar./Apr. 1998, pp. 374-380.

[18] BRAHMANANDA REDDY, T. - AMARNATH, J. - SUBBARAYUDU, D.: Improvement of DTC performance by using hybrid space vector Pulsewidth modulation algorithm: International Review of Electrical Engineering, Vol. 2, No. 1, July-Aug. 2007, pp. 593-600.

[19] RAVISANKAR REDDY, N. - BRAHMANANDA REDDY, T. - AMARNATH, J. - SUBBA RAYUDU, D.: Hybrid PWM Algorithm for Vector Controlled Induction Motor Drive without Angle Estimation for Reduced Current Ripple, ICGSTACSE journal, Vol. 9, Issue 3, pp. 41-49, Dec. 2009, ASME BPVC-I-2004, Boiler and Pressure Vessel Code, Section 1 - Power Boilers.

Received May 25, 2012, accepted December 17, 2012

\section{BIOGRAPHIES}

P. Nagasekhar Reddy graduated from Bangalore University, Bangalore in the year 2000. He received M.Tech degree from Jawaharlal Nehru technological University, Hyderabad, India in 2005 . He is presently working as Sr. Assistant Professor, MGIT, Hyderabad. Also, he is pursuing his Ph.D in Jawaharlal Nehru technological University, Hyderabad, India. He presented 14 research papers in various national and international conferences and journals. His research interests include PWM techniques and control of electrical drives.

J. Amarnath graduated from Osmania University in the year 1982, M.E from Andhra University in the year 1984 and Ph.D from J.N.T. University, Hyderabad in the year 2001. He is presently Professor in Electrical and Electronics Engineering Department, JNTU College of Engineering, Hyderabad and also he is the Chairman, Board of studies in Electrical and Electronics Engineering, JNTU College of Engineering, Hyderabad. He presented more than 100 research papers in various national and international conferences and journals. His research areas include Gas Insulated Substations, High Voltage Engineering, Power Systems and Electrical Drives.

P. Linga Reddy received M.E from Andhra University, Visakhapatnam in 1965 and Ph.D degree from Indian Institute of Technology, Delhi in 1978. He is presently working as Professor at K.L. University, Guntur, India. He is having more than 45 years experience in teaching. $\mathrm{He}$ published more than 15 papers in various national and international journals and conferences. His research interests include control systems and control of electrical drives. 